\title{
Un journaliste du Chicago Tribune remporte le prix Pulitzer pour ses articles sur le projet "Diversité du génome humain "
}

Informer le grand public des progrès scientifiques, être clair, captivant, et en même temps honnête et objectif n'est pas chose facile. En génétique humaine encore moins que dans d'autres disciplines. Dès les premières velléités d'exploration du génome humain se sont déchaînées passions, controverses et luttes de pouvoir. Depuis le projet HUGO (Human Genome Organisation) lancé à grand fracas pour coordonner la recherche internationale il y a dix ans déjà, dont l'évolution fut relatée régulièrement dans les colonnes de médecine/sciences, en particulier par Bertrand Jordan dans sa série de Chroniques génomiques [1], depuis l'émoi suscité par la volonté du NIH (National Institute of Health) de breveter les séquences génomiques [2-5], l'histoire de l'exploration de notre génome est pleine de bruit et de fureur.

Parallèlement au séquençage et à l'inventaire de tous les gènes humains, un autre projet, celui de l'étude de la Diversité du Génome dans les Populations Humaines, ou HGDP (Human Genome Diversity Project) plaidé depuis 1991 avec énergie et conviction par Luca Cavalli-Sforza de l'Université de Stanford (Californie, USA) [6] (m/s 1991, $n^{\circ} 9$, p. 975), n'a pas manqué, lui non plus, d'entraîner de violentes polémiques. C'est pour en avoir relaté l'histoire, dans le Chicago Tribune, que Paul Salopek, un journaliste américain de 36 ans, passionné d'anthropologie et grand voyageur, vient de recevoir un prix Pulitzer [7-9]. Ces prix, on le sait, furent institués en 1917 par Joseph Pulitzer, journaliste américain d'origine hongroise devenu immensément riche, qui prit conscience de l'importante responsabilité des journalistes en matière d'information du entre autres, ceux qui, par des articles exhaustifs et impartiaux, sont parvenus à faire le point sur des sujets brûlants de l'actualité.

Initialement, ce HGDP, inventaire de la diversité des êtres humains vivant aujourd'hui sur la planète, ne semblait pas poser de problèmes. Il fallait, pendant qu'il est encore temps, recueillir le génome de toutes les populations isolées dans le monde avant qu'elles ne disparaissent ou ne se mélangent, et le transmettre aux hommes du troisième millénaire comme une de ces précieuses ressources humaines qu'il convient de préserver. Cette collection devait refléter nos parentés et nos différences et révéler les secrets de notre histoire: "tous parents, tous différents", mais tous à part entière représentants de la grande famille des hommes. Il devait concerner non seulement les généticiens, mais éclairer aussi les anthropologues, les archéologues, les linguistes. Et pour ce faire, des appels furent lancés aux laboratoires du monde entier afin de recueillir le maximum de prélèvements de sang de toutes les ethnies existant sur terre, surtout de celles en voie d'extinction (comme de nombreuses tribus indiennes d'Amérique, ainsi que les Pygmées, Bushmen, Basques, Lapons, Aïnous, pour n'en citer que quelques-unes). Le projet devait durer cinq ans, coûter 25 millions de dollars, recueillir 10000 échantillons d'au moins 400 groupes ethniques. Il n'était, en fait, que la mise au grand jour d'une activité entreprise depuis des décennies. Ainsi, Ken Weiss, le coordonnateur du HGDP aux USA, recèle dans ses congélateurs l'ADN de près de 12000 Indiens Yanomamo, prélevé par des anthropologues dans la forêt brésilienne, près des chutes de l'Orénoque, bien avant que cette malheu- reuse population ne soit dispersée par les chercheurs d'or. Les habitats furent bouleversés par les pistes d'atterrissage et les coups de barres à mines. Décimée par les maladies du monde "civilisé ", et parfois à coups de fusil, la tribu des Yanomamo, composée de plusieurs dizaines de milliers d'hommes au début du siècle, n'en compte guère plus à présent que 10000 .

Mais ces collectes ne sont pas forcément faites pour le bien des hommes, et, en outre, elles sont loin d'être toujours désintéressées. Les responsables des firmes pharmaceutiques ont gardé à l'esprit l'étrange découverte faite en Nouvelle-Guinée à la fin des années 1980 quand on montra que les Papous de la tribu Hagahai avaient, dans leurs lymphocytes, un virus leucémogène auquel ils restaient totalement insensibles. D'où cet appât d'une nouvelle mine d'or, puisée dans les gènes des populations primitives, pour la production de médicaments lucratifs. Pourtant, chez les Hagahai, la collecte avait été assortie d'une information et d'une promesse: si le gène conférant la résistance à ce virus, isolé sous licence des États-Unis, ouvrait la voie à un traitement antileucémique, la moitié des bénéfices seraient reversés à la population Hagahai. C'est à partir de là que le scandale a commencé: comment un gouvernement osait-il se permettre de breveter l'héritage génétique d'un autre peuple? Bien que les recherches soient suspendues, l'accusation de néocolonialisme scientifique enflamma le monde. Une coalition panaméricaine des peuples indigènes contre la biopiraterie fut créée. Elle compte une trentaine d'organisations. Un documentaire anglais, intitulé "Les chasseurs de gènes" fut diffusé pour montrer les pratiques douteuses des 
compagnies pharmaceutiques à la recherche de diabétiques dans la jungle de Colombie (bleed and run!). Mais les résistances ne vinrent pas seulement des groupes minoritaires luttant pour la survie de leur langue et de leur culture. Des scientifiques mirent en doute l'intérêt du projet, ne serait-ce qu'en raison des inconnues de l'horloge biologique, des migrations de populations et du fossé conceptuel entre biologie et culture. Les institutions devinrent de plus en plus réticentes à attribuer des subventions à une entreprise si vaste, si controversée et assez floue dans ses objectifs. Les comités d'éthique, sceptiques quant à l'obtention de consentements éclairés de la part des groupes aborigènes, insistèrent sur les risques de violation des droits de l'homme et de résurgence de racisme. Pourtant, les résultats préliminaires de ces études devraient désamorcer les attitudes racistes, car ils démontrent la grande communauté des patrimoines génétiques de groupes humains très éloignés les uns des autres. Ils révèlent les différences importantes au sein de groupes en apparence homogènes. Ils confirment l'origine africaine de l'humanité et l'énorme diversité génétique des populations du continent africain $\left(m / s\right.$ 1995, $n^{\circ} 8$, p. 1187). Déjà, ils nous informent sur les Basques, un des plus vieux peuples de l'Europe, et sur les Finnois, un des derniers venus.

Patiemment, et malgré toutes les attaques dont il fait l'objet, Luca Cavalli-Sforza tente de convaincre les pouvoirs publics et les institutions. Depuis que le projet HGDP a reçu une volée de bois vert lors de sa demande de reconnaissance et de soutien de la part de l'Unesco en sep- tembre $1995[10,11]$, il est désormais accompagné d'une charte de bonne conduite, le MEP (Model Ethical Protocol). Celui-ci repose sur deux principes de base: (1) établir un partenariat entre les chercheurs et la population concernée; (2) obtenir un consentement éclairé des individus, ou des groupes (ce dernier point risque d'achopper en Europe où seuls, les individus sont pris en compte). Après de nombreuses réunions, dont deux Euroconférences organisées par le Comité Européen de HUGO (en 1995 et 1997), un rapport de 81 pages fut effectué sur la demande du NIH et de la NSF (National Science Foundation) par un comité du conseil de la recherche américain (NRC) dont les conclusions soutenaient l'intérêt du projet [12]. Premier pas vers un financement... en même temps qu'une régularisation de tous ces prélèvements déjà effectués anarchiquement un peu partout, ADN congelés ou lignées cellulaires immortalisées, conservés dans les laboratoires bien avant que les recommandations éthiques ne soient désormais devenues des lois dans de nombreux pays. Le temps presse car d'autres initiatives prennent corps, comme le monopole «deCODE» en Islande. Avec la bénédiction du gouvernement islandais, des études génétiques ont commencé sur les habitants de cette île qui descendent à peu près tous d'un peuplement remontant à environ 10 siècles. Elles sont étayées par de solides arbres généalogiques. Elles seront exclusivement réalisées sur 5 ans, pour 200 millions de dollars, par la compagnie Hoffmann-La Roche (Bâle, Suisse) qui mettra gratuitement à la disposition des Islandais tous les médicaments résultant de ces recherches. Ce contrat viole les libertés individuelles, favorise des groupes de personnes mais il préfigure peutêtre les méthodes d'analyse génétique des populations dans l'avenir. Avec clarté, aisance, Paul Salopek a su exposer le projet «Diversité du Génome Humain » et décrire objectivement le tableau du maelström qui tourbillonne autour de lui. A l'annonce de son prix, il se sentit doublement heureux car, dit-il «être récompensé pour un travail qui vous a passionné est deux fois gratifiant».

Pour éclairer les débats de société de demain, il nous faudrait beaucoup de journalistes scientifiques de cette qualité.

S.G.

1. Jordan B. Chroniques génomiques. Med $\mathrm{Sci}$ $1990 ; 6: 157-9$

2. CCNE. La non-commercialisation du génome humain. Med Sci 1991; 7 : 1114-6.

3. Kahn A. Un audit des autorités fédérales américaines sur la brevetabilité du génome. Med Sci $1992 ; 8: 617-9$

4. Pour un libre accès aux informations sur le génome. Une première liste de signatures. Med Sci 1993; 9 : 113 .

5. Claverie JM. Éthique et génome: une perspective américaine. Med Sci 1994; 10: 129-32.

6. Cavalli-Sforza LL, Wilson AC, Cantor CR, CookDeegan RM, King MC. Call for a worldwide survey of human genetic diversity: a vanishing opportunity for the Human Genome project. Genomics $1991 ; 11: 490-1$.

7. McRoberts F. Tribune writer joins Pulitzer history. Chicago Tribune, 15 avril 1998.

8. Salopek P. Unlocking the rainbow. Chicago Tribune, 27 avril 1997.

9. Salopek P. Genes offer sampling of hope and fear. Chicago Tribune, 28 avril 1997.

10. Butler D. Genetic diversity proposal fails to impress international ethics panel. Nature 1995; 377: 373 .

11. Macilwain C. Diversity project « does not merit federal funding ». Nature 1997; 389: 774.

12. Pennisi E. NRC OKs long-delaved survey of human genome diversity. Science 1997; 278: 568. 